\title{
Probabilistic Analysis of Tunnel Face Stability below River Using Bayesian Framework
}

\author{
Weiping Liu $\mathbb{D},{ }^{1}$ Xiaoyan Luo, ${ }^{2}$ Jinsong Huang, ${ }^{3}$ Lina Hu $\left(\mathbb{D},{ }^{1}\right.$ and Mingfu Fu ${ }^{1,4}$ \\ ${ }^{1}$ School of Civil Engineering and Architecture, Nanchang University, Nanchang 330031, China \\ ${ }^{2}$ Jiangxi Science and Technology Normal University, Nanchang 330013, China \\ ${ }^{3}$ ARC Centre of Excellence for Geotechnical Science and Engineering, University of Newcastle, Callaghan, NSW 2308, Australia \\ ${ }^{4}$ School of Civil Engineering and Architecture, Nanchang Institute of Technology, Nanchang 330099, China
}

Correspondence should be addressed to Lina Hu; hulina@ncu.edu.cn

Received 28 February 2018; Accepted 10 May 2018; Published 6 June 2018

Academic Editor: Eric Feulvarch

Copyright (C) 2018 Weiping Liu et al. This is an open access article distributed under the Creative Commons Attribution License, which permits unrestricted use, distribution, and reproduction in any medium, provided the original work is properly cited.

\begin{abstract}
A key issue in assessment on tunnel face stability is a reliable evaluation of required support pressure on the tunnel face and its variations during tunnel excavation. In this paper, a Bayesian framework involving Markov Chain Monte Carlo (MCMC) simulation is implemented to estimate the uncertainties of limit support pressure. The probabilistic analysis for the three-dimensional face stability of tunnel below river is presented. The friction angle and cohesion are considered as random variables. The uncertainties of friction angle and cohesion and their effects on tunnel face stability prediction are evaluated using the Bayesian method. The threedimensional model of tunnel face stability below river is based on the limit equilibrium theory and is adopted for the probabilistic analysis. The results show that the posterior uncertainty bounds of friction angle and cohesion are much narrower than the prior ones, implying that the reduction of uncertainty in cohesion and friction significantly reduces the uncertainty of limit support pressure. The uncertainty encompassed in strength parameters are greatly reduced by the MCMC simulation. By conducting uncertainty analysis, MCMC simulation exhibits powerful capability for improving the reliability and accuracy of computational time and calculations.
\end{abstract}

\section{Introduction}

Valid estimation of the tunnel face stability under excavation requires a reliable evaluation of limit support pressure which prevents soil collapse. This issue has been extensively studied with limit equilibrium method [1], numerical methods [2,3], and experimental methods [4]. The limit equilibrium method is commonly used for predicting limit support pressure, being relatively simple compared with finite element analysis. Investigations showed that soil parameters, such as cohesion and friction angle, are the most important soil properties for influencing the limit support pressure [5]. Therefore, accurate estimation of soil strength parameters is necessary for assessment of the tunnel face stability under tunnel excavation.

Normally the mean values of soil parameters are used in deterministic analysis. Although the method can deliver accurate analytical results of support pressure, it requires the input parameters for every calculation point in situ and cannot control the spatial variability of the input parameters. In fact, geotechnical materials are natural materials, and their properties are affected by various spatially variable factors during their formation processes. The inherent spatial variability has been considered as one of the major sources of uncertainties $[6,7]$ and can be modeled using stochastic analysis [8].

A major difficulty in estimating accurate limit support pressure arises from the uncertainties incorporated in the input parameters of the computer model. The input strength parameters, such as cohesion and friction angle, are usually determined by direct measurements in laboratory. These samples will be disturbed in the process of testing. Meanwhile, the test conditions in laboratory cannot be exactly the same as in situ. This also leads to a significant uncertainty in predicting the limit support pressure for keeping tunnel face stability. This uncertainty poses challenges for obtaining 
reliable design of tunnel excavation. The stochastic approach can improve the traditional deterministic methods for taking the uncertainties of the parameters into account.

In practice, tunnel face collapse prediction can be formulated as a classification. Many studies have been performed to analyze the stability of tunnel face [9]. Mollon et al. [10,11] use response surface method to perform probabilistic analysis of the face stability of tunnel. Li et al. [12] use the firstorder reliability method and Monte Carlo simulation to carry out reliability analysis of a circular tunnel subjected to a hydrostatic stress field. Oreste [13] presents a probabilistic design approach for the tunnel taking into account the uncertainties of the rock mass quality index. Celestino et al. [14] evaluate the probability of failure according to load and resistance factor design principles. Langford et al. [15] use a modified point estimate method to design the tunnel. Lu et al. [16] evaluate failure probability of each failure mode of a rock tunnel by the first-order reliability method and the response surface method via an iterative procedure. Eshraghi et al. [17] study the face stability of TBD-driven tunnel in heterogeneous soil using probabilistic approach.

Bayesian approach can update the current state of knowledge about the model parameters based on the measurement data [18]. Many successful applications of Bayesian approach have been reported, e.g., estimation of the parameters of hydrological model [19], confidence interval of SWCC [20], and braced excavation [21]. Although previous studies have been done on the probability analysis of tunnel, a systematic Bayesian framework and Markov Chain Monte Carlo (MCMC) simulation for the probabilistic analysis has not yet been developed. The effect of uncertainties of soil parameters on prediction uncertainty of tunnel face stability below river using a Bayesian framework has not yet been investigated.

In this paper, the probability is associated with the different parameters which are governing the tunnel face stability and furthermore detailed in the following. The soil strength parameters, such as friction angle and cohesion, are assumed as random variables. The tunnel face below river is in the homogeneous soils. The three-dimensional model of tunnel face stability below river is based on the limit equilibrium theory and is adopted for the probabilistic analysis. The probabilities analysis and parameters uncertainty estimation are performed using the Markov Chain Monte Carlo (MCMC) simulation method which is good efficiency for highly nonlinear problem [22], with a delayed rejection adaptive metropolis (DRAM) [23] algorithm. The effects of uncertainty of strength parameters on the limit support pressure are discussed using the proposed Bayesian framework.

\section{Limit Support Pressure}

Wedge analysis [24] based on the limit equilibrium theory is adopted the limit support pressure for the face stability of a tunnel below river. A simple failure mechanism which idealizes the three-dimensional mode of tunnel face is shown in Figure 1. The collapsing soil in front of the tunnel is schematized as a triangular wedge; the wedge is assumed as a rigid body. $B, H, L$ are the width, length, and height of the

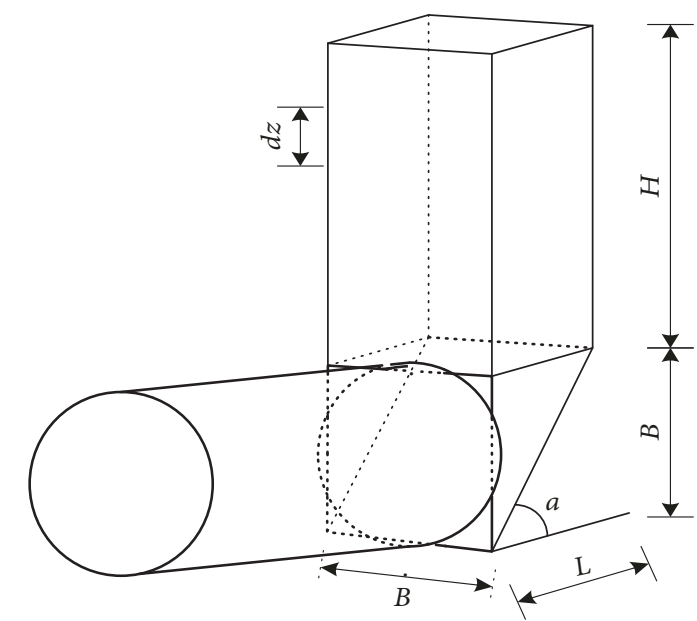

Figure 1: Wedge stability model.

prism in Figure 1, respectively. The length $L$ of prism is $L=$ $B / \tan \alpha$, and the inclination of wedge is $\alpha=45^{\circ}+\varphi / 2$. This three-dimensional model is first proposed by Horn [25], and a right-angled prism extends from the tunnel crown to the surface. The Mohr-Coulomb failure condition with friction angle $\varphi$ and cohesion $c$ is assumed. Terzaghi's formula [26] has generally been adopted as vertical earth pressure acting the tunnel.

The circular cross-section of the tunnel is approximated by a square whose sides are as long as the circular tunnel diameter $D$ and has the same area.

$$
B^{2}=\frac{1}{4} \pi D^{2}
$$

Considering an element has dimension $d z$ within prism of height $H$ as shown in Figure 1, the upper and lower vertical force of element are, respectively,

$$
\begin{aligned}
& P_{1}=A \sigma_{v}, \\
& P_{2}=A\left(\sigma_{v}+d \sigma_{v}\right)
\end{aligned}
$$

where $\sigma_{v}$ is the effective earth pressure from the overlying prism and $A$ is the cross-sectional area of prism.

Vertical friction applied to lateral of the element is

$$
f=k_{0} U \sigma_{v} \tan \varphi d z+U c d z
$$

where $U$ is the girth of prism; $k_{0}$ is coefficient of earth pressure at rest, $k_{0}=1-\sin \varphi$.

The vertical equilibrium equation of $d z$ reads as follows:

$$
k_{0} U \sigma_{v} \tan \varphi d z+U c d z+A\left(\sigma_{v}+d \sigma_{v}\right)-A \sigma_{v}=\gamma A d z
$$

where $\gamma$ is the volumetric weight of the soil.

From the equilibrium equation (4) of the forces acting on the wedge, with boundary conditions $z=0, \sigma_{v}=p_{0}$, the effective earth pressure acting upon the wedge can be obtained as

$$
\sigma_{v}=\frac{A \gamma-U c}{U k_{0} \tan \varphi}\left(1-e^{-z U k_{0} \tan \varphi / A}\right)+p_{0} e^{-z U k_{0} \tan \varphi / A}
$$

where $p_{0}$ is the surcharge on the surface. 


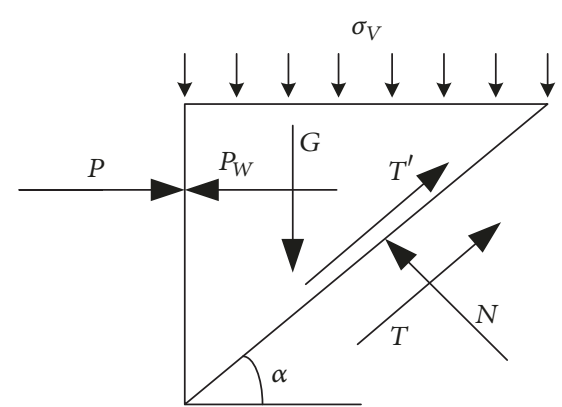

FIGURE 2: Forces acting upon the wedge.

For the sake of simplicity, the soil of wedge is considered to be homogeneous. Assuming the failure criterion holds along the failure face, a static equilibrium equation can be set up. When a shield tunnel is located below the river, the stability analysis of the shield tunnel face needs to consider the influence of pore water pressure. The pore water pressure usually is considered an external force [27] and the forces acting upon the wedge at the tunnel face illustrates in Figure 2. A hydrostatic distribution of pore water pressures along the slip surface is assumed. There are effective earth stress $\sigma_{v}$ at the wedge-prism-interface, the self-weight of wedge $G=\gamma B^{3} / 2 \tan \alpha$, the support force $P$ at the tunnel face, the normal force $N$ on the inclined sliding surface, the shear forces $T$ on the inclined as well as on the sliding surface, the symmetric normal force $N^{\prime}$, and the shear force $T^{\prime}$ on the two lateral surfaces of the wedge.

The vertical mean stress $\sigma_{z}^{\prime}$ on the inclined sliding surface is

$$
\sigma_{z}^{\prime}=\frac{2 \sigma_{v}}{3}+\frac{B \gamma}{3}
$$

The shear forces $T$ on the inclined sliding surface is

$$
T=\frac{c B^{2}}{\sin \alpha}+N \tan \varphi
$$

The shear force $T^{\prime}$ acting on the two sides of the wedge can be written as follows:

$$
T^{\prime}=\frac{B^{2}}{2 \tan \alpha}\left(c+k_{0} \sigma_{z}^{\prime} \tan \varphi\right)
$$

Not taking the infiltration in excavation face into account, the overburden strata are assumed to be permeable with high permeability, such as sand and gravel. So a complete hydraulic connection exists between the river water and groundwater. In this sense, the pore water pressure generated by river water can be expressed as

$$
P_{w}=B^{2}\left(\sum \gamma_{w} z_{i}+\gamma_{w} h\right)
$$

where $\gamma_{w}$ is the unit weight of water and $z_{i}$ is the thickness of stratum no. $i$, which is located above the centre point of tunnel face.
By considering the water pressure and equating force in the vertical and horizontal direction, the limit support force on the tunnel face is

$$
\begin{aligned}
P= & \varepsilon\left(\sigma_{v} B L+G\right)-\left(\frac{c B^{2}}{\sin \alpha}+2 T^{\prime}\right)(\varepsilon \sin \alpha+\cos \alpha) \\
& +P_{w}
\end{aligned}
$$

where $\varepsilon=(\sin \alpha-\tan \varphi \cos \alpha) /(\cos \alpha+\tan \varphi \sin \alpha)$ and $\sigma_{v}$ is calculated in terms of effective stresses.

The support pressure is simplified and considered uniform, and the minimum support pressure termed as limit support pressure which keeps the tunnel face stable is expressed as

$$
\begin{aligned}
\sigma_{T} & =\frac{1}{B^{2}}\left[\varepsilon\left(\sigma_{v} B L+G\right)\right. \\
& \left.-\left(\frac{c B^{2}}{\sin \alpha}+2 T^{\prime}\right)(\varepsilon \sin \alpha+\cos \alpha)+P_{w}\right]
\end{aligned}
$$

This would provide a simple design method for limit support pressure on the tunnel face. Effect of a multilayered overburden also can be taken into account. In this paper, this mechanism will be used for the probabilistic analysis.

\section{Bayesian Framework}

Within a Bayesian framework, inferences are made about the parameters of interest by a probability distribution given the data [28]. Bayesian framework is applied to estimate the values of unknown parameters of a model about which some prior information may be available. According to the Bayes' theorem, the posterior distribution of $\theta$ is proportional to the product of the likelihood function and the prior distribution function [29]. Bayes' formula can be written as follows:

$$
P(\theta \mid y)=\frac{L(y \mid \theta) P(\theta)}{P(y)}
$$

where $P(\theta)$ is the prior probability distribution of the parameters; $L(y \mid \theta)$ is the likelihood function and incorporates the statistical as well as the mechanistic relationships among the predictors and variables; $P(\theta \mid y)$ is the posterior distribution of the parameters; $P(y)$ is the normalizing constant to make the probability density function valid. $\theta$ is vector of uncertain input parameters. The prior distribution of $\theta$ and measured data can be integrated using a systematic way.

The error or difference between the actual performance and the model prediction is defined as the model correction factor $\varepsilon$ which can be used to characterize model uncertainty.

$$
y=g(\theta)+\varepsilon
$$

where $y$ is the actual limit support pressure; $g(\theta)$ is predicting limit support pressure using the given tunnel face stability model; $\theta$ is vector of uncertain input parameters.

The likelihood function gives a measure of the agreement between the available data and the corresponding model 
output. Assuming that error $\varepsilon$ is to be normally distributed, the likelihood function is the conditional probability density function of $\theta$ and can be written as

$$
L(y \mid \theta)=\phi\left[\frac{y-g(\theta)-\mu_{\varepsilon}}{\sigma_{\varepsilon}}\right]
$$

where $\phi$ is the probability density function of standard normal variable; $\mu_{\varepsilon}$ and $\sigma_{\varepsilon}$ are the mean and standard deviation of errors, respectively.

\section{Markov Chain Monte Carlo Method}

Bayesian updating can be achieved using Bayesian framework, when conjugate priors are given. The posterior distribution function of input parameters and model predicted response cannot be derived through analytical means. An alternative approach is to use a MCMC method to obtain the numerical summarization of the posterior distribution. Therefore, random sampling methods are needed to generate samples from the posterior distribution function. These posterior distributions are obtained using the MCMC simulation, which is an effective random sampling method. The MCMC simulation can maintain adequate sampling density as the number of parameter increases and compute efficiently which has gained popularity in recent years to sample the posterior probability density function [30]. It can handle efficiently problems with a large number of random variables and is very flexible to any type of prior distribution. The idea of the MCMC simulation is to simulate a random walk across the parameter space by drawing samples from the approximate posterior distribution and improving those draws until the distribution converges to the target posterior distribution. Delayed rejection adaptive metropolis algorithm (DRAM) [23] is the widely used algorithms in the MCMC method. A multivariate normal distribution with a mean vector defined by the current value and the covariance matrix $C_{i}$ is considered as

$$
C_{i}= \begin{cases}C_{0} & i \leq i_{0} \\ s_{d} \operatorname{cov}\left(\zeta_{0}, \ldots, \zeta_{i-1}\right)+s_{d} \delta I_{d} & i>i_{0}\end{cases}
$$

where $C_{0}$ is the initial covariance to start the adaptation procedure; $s_{d}$ is a parameter that depends only the dimension $d$ of the state space, $s_{d}=2.4^{2} / d ; \operatorname{cov}\left(\zeta_{0}, \ldots, \zeta_{i-1}\right)$ is the covariance of previous samples; $I_{d}$ denotes the d-dimensional identity matrix; $\delta$ is a small constant.

The definition of the empirical covariance matrix determined

$$
\operatorname{cov}\left(\zeta_{0}, \ldots, \zeta_{k}\right)=\frac{1}{k}\left(\sum_{i=1}^{k} \zeta_{i} \zeta_{i}^{T}-(k+1) \bar{\zeta}_{k} \bar{\zeta}_{k}^{T}\right)
$$

where $\bar{\zeta}_{k}=(1 /(k+1)) \sum_{i=0}^{k} \zeta_{i}$.
TABle 1: Prior distributions.

\begin{tabular}{lccc}
\hline Parameter & Mean & Std. dev. & COV \\
\hline$\varphi$ & 30 & 4.5 & 0.15 \\
$c$ & 5 & 1 & 0.20 \\
\hline
\end{tabular}

For $i>i_{0}$, substituting (16) into (15), the covariance satisfies the recursive equation as

$$
\begin{aligned}
C_{n+1}= & \frac{n-1}{n} C_{n} \\
& +\frac{s_{d}}{n}\left(n \bar{\zeta}_{n-1} \bar{\zeta}_{n-1}^{T}-(n+1) \bar{\zeta}_{n} \bar{\zeta}_{n}^{T}+\zeta_{n} \zeta_{n}^{T}+\varepsilon I_{d}\right)
\end{aligned}
$$

In the delayed rejection algorithm, the proposed sample $\zeta_{i}^{(1)}$ is accepted with the probability.

$$
\alpha_{1}\left(\zeta_{i-1}, \zeta_{i}^{(1)}\right)=\min \left\{1, \frac{p\left(\zeta_{i}^{(1)} \mid D\right) q_{1}\left(\zeta_{i}^{(1)}, \zeta_{i-1}\right)}{p\left(\zeta_{i-1} \mid D\right) q_{1}\left(\zeta_{i-1}, \zeta_{i}^{(1)}\right)}\right\}
$$

where $q_{1}$ is the first proposal distribution.

The second stage proposal is accepted with probability if the $\zeta_{i}^{(1)}$ is rejected.

$$
\begin{aligned}
& \alpha_{2}\left(\zeta_{i-1}, \zeta_{i}^{(2)}\right)=\min \{1, \\
& \frac{p\left(\zeta_{i}^{(2)} \mid D\right) q_{1}\left(\zeta_{i}^{(2)}, \zeta_{i}^{(1)}\right) q_{2}\left(\zeta_{i}^{(2)}, \zeta_{i}^{(1)}, \zeta_{i-1}\right)}{p\left(\zeta_{i-1} \mid D\right) q_{1}\left(\zeta_{i-1}, \zeta_{i}^{(1)}\right) q_{2}\left(\zeta_{i-1}, \zeta_{i}^{(1)}, \zeta_{i}^{(2)}\right)} \\
& \left.\qquad \frac{\left[1-\alpha_{1}\left(\zeta_{i}^{(2)}, \zeta_{i}^{(1)}\right)\right]}{\left[1-\alpha_{1}\left(\zeta_{i-1}, \zeta_{i}^{(1)}\right)\right]}\right\}
\end{aligned}
$$

where $q_{2}$ is the second proposal distribution.

This process of delaying rejection can be iterated.

\section{Probabilistic Analysis}

Numerous test investigations and numerical studies of tunnel face stability have illustrated that the friction angle $\varphi$ and cohesion $c$ have significantly influence the accuracy of the predicting limit support pressure. In this study, only the friction angle and cohesion are considered as random variables. The updating process starts with assumed with the prior distributions for the soil strength parameter of friction angle and cohesion, which are considered important for limit support pressure on tunnel face.

The friction angel and cohesion are considered as random input parameters with normal variables. In this study, the respective means of friction angle and cohesion are denoted as $\mu_{\varphi}=30^{\circ}, \mu_{c}=5 \mathrm{kPa}$, respectively. The prior coefficient of variation (COV) values of the friction angle and cohesion are assumed to be $\mathrm{COV}_{\varphi}=15 \%, \mathrm{COV}_{\mathrm{c}}=20 \%$ [31], respectively. The prior distributions and basic statistics of the soil parameters are summarized in Table 1.

For probabilistic analysis of support stress on tunnel face, variation of friction angle and cohesion are considered. Other 


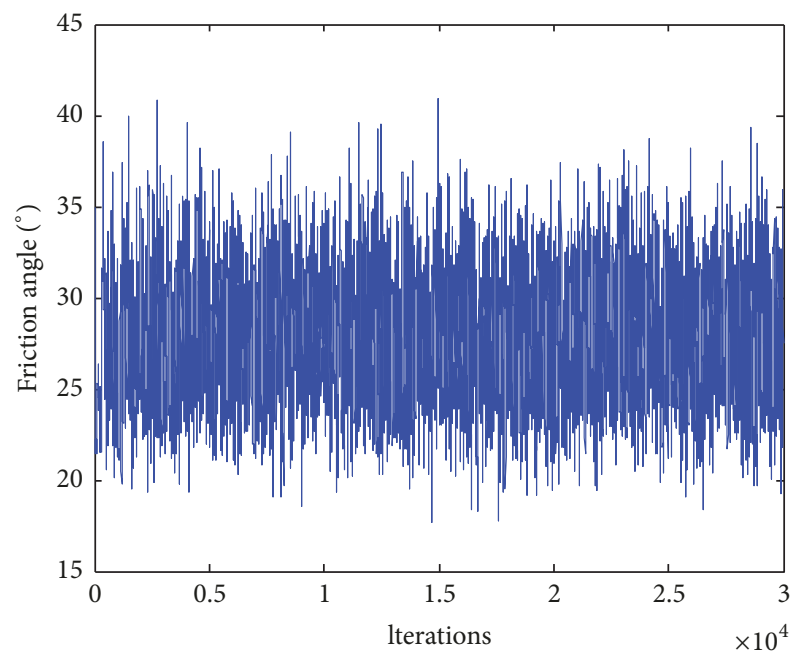

(a)

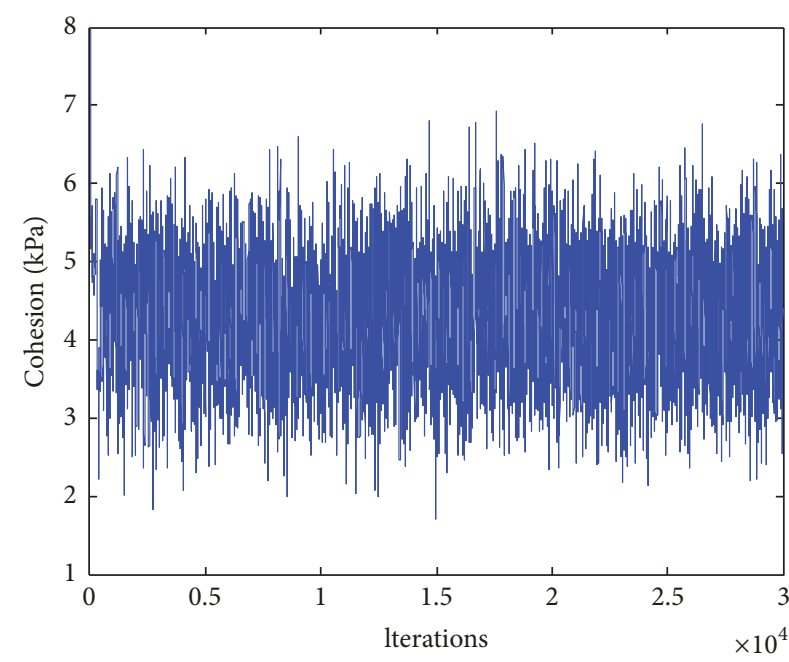

(b)

FIGURE 3: Plot of samples with MCMC simulation steps.

parameters come from the crossing Ganjiang River tunnel and are used as follows: saturated unit weight $\gamma_{\text {sat }}=20$ $\mathrm{KN} / \mathrm{m}^{3}$, the tunnel diameter $D=6 \mathrm{~m}$, the tunnel cover depth $H=12 \mathrm{~m}$, and the water depth in river $h=10 \mathrm{~m}$. We consider a measurement outcome of limit support stress $\sigma_{T}=254.68$ $\mathrm{kPa}$ which corresponds to the measured mean values of friction angle $28^{\circ}$ and cohesion $4 \mathrm{kPa}$, respectively, according to the laboratory test results of soil in site. The adopted model functions are limit support stress which is provided in (11). Based on the Bayesian framework described in the previous section, the material properties of the soils are updated using the assumed the limit support pressure $254.68 \mathrm{kPa}$.

The chains with total number of evaluations equal to 30,000 are used in MCMC simulation with a DEAM algorithm, and the posterior samples generated are shown in Figure 3. From the Figure 3, it shows that the chains can quickly converge to a stable posterior distribution. The Markov chain is effective in collecting representative samples. After verifying that the distribution of the values converged to the posterior distribution, the distribution of the parameters can be used to produce optimum simulations and generate an estimation of the model uncertainty. The initial 5,000 samples are discarded because the Markov chain has not stabilized. The remaining 25,000 samples are used as the posterior distribution samples.

\section{Results and Discusses}

6.1. Posterior Distribution of Input Parameters. Since the samples are generated by MCMC method, the posterior distributions of the parameters are computed using the chains of the two MCMC simulations. Figures 4 and 5 illustrate the prior and posterior distributions of the friction angle and cohesion, respectively. When additional knowledge is available, the prior distributions of the input parameters can be reformulate. From Figures 4 and 5, it is obvious that the parameters of friction angle and cohesion are concentrated

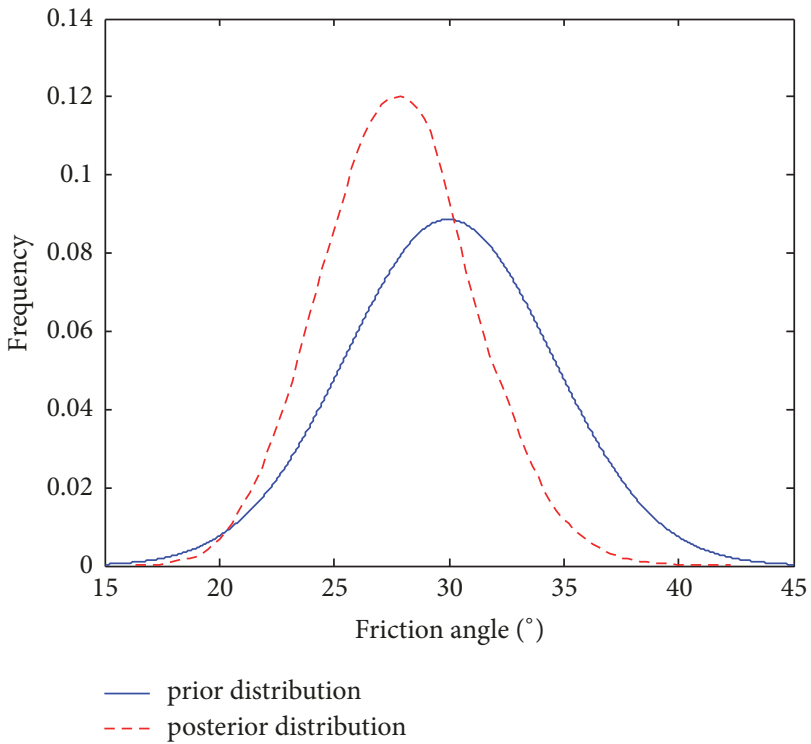

FIgURE 4: Prior and posterior distribution of friction angle.

within a small region and show normal shape. The posterior mean, standard deviation, and COV value are summarized in Table 2 using the remaining 25,000 samples. The "best" parameter set is typically created by computing the mean for each input parameters $[32,33]$. The mean of posterior distribution for the friction angle and cohesion is also smaller than that of prior distribution, the updated mean values of the friction angle, and cohesion decrease from $30^{\circ}$ to $27.816^{\circ}$ and from $5 \mathrm{kPa}$ to $4.268 \mathrm{kPa}$, respectively. The means of values are getting increasingly closer to the measured parameters (friction angel $28^{\circ}$ and cohesion $4 \mathrm{kPa}$ ) which express the ability of the MCMC method to converge to the measured parameters. 
TABLE 2: Statistic of posterior distribution parameters.

\begin{tabular}{lccc}
\hline Parameter & Mean & Std. dev. & COV \\
\hline$\varphi$ & 27.816 & 3.181 & 0.114 \\
$c$ & 4.268 & 0.697 & 0.163 \\
\hline
\end{tabular}

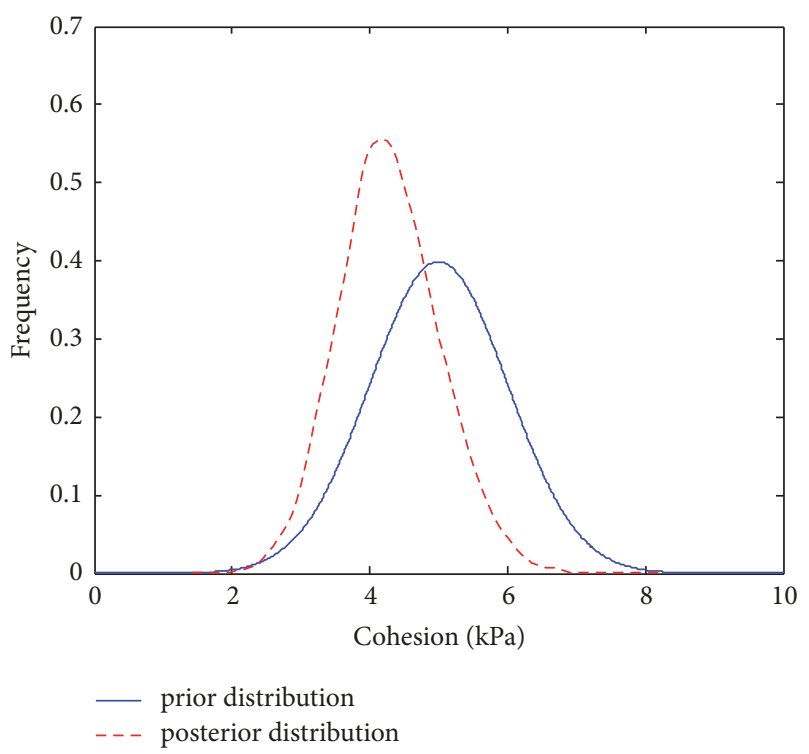

Figure 5: Prior and posterior distribution of cohesion.

According to Table 2, the prior and posterior standard deviations are also given for a comparison. The distribution of friction angle and cohesion is significantly modified via Bayesian updating. The standard deviation of friction angle is reduced from 0.15 to 0.114 . The standard deviation of cohesion is reduced from 0.2 to 0.163 . Compared to the COVs of the soil parameters of prior and posterior distribution, the COVs of both friction angle and cohesion are reduced with the application of the Bayesian framework. The posterior density will be more concentrated and more informative than the prior density. The COVs for both friction angle and cohesion are reduced, implying reduction in the uncertainty of strength parameters. The updated parameters show that the uncertainty of friction angle and cohesion is reduced, which reflects the measurement on the variable.

6.2. Predicted Limit Support Pressure. In this section, the probability distribution of the limit support stress is determined for a given condition. Using updated soil parameters of friction angle $\varphi$ and cohesion $c$ presented as posterior distributions, the limit support pressure on tunnel face can be estimated. The limit support pressures obtained by the posterior and prior distribution are shown in Figure 6, respectively. The outcomes resulting from prior and posterior parameters are demonstrated. The cumulative distributions are shown in Figure 7. The distributions have considerable effects on limit support pressure on tunnel face. With all the soil strength parameters updated via Bayesian framework, the three-dimensional model of tunnel face stability is able to compute probabilities more accurately and realistically.

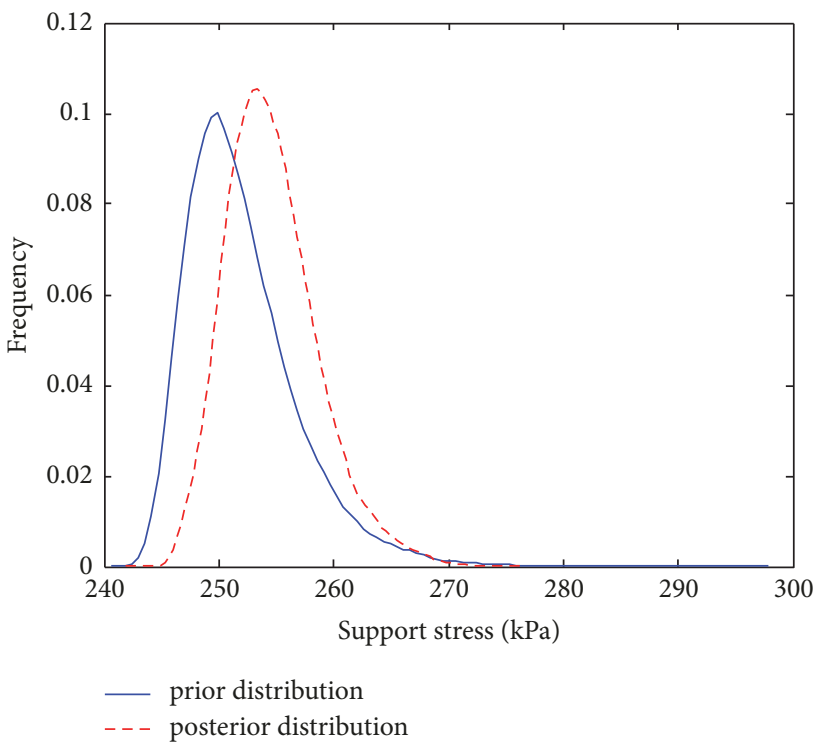

FIgURE 6: Posterior distribution of the limit support stress.

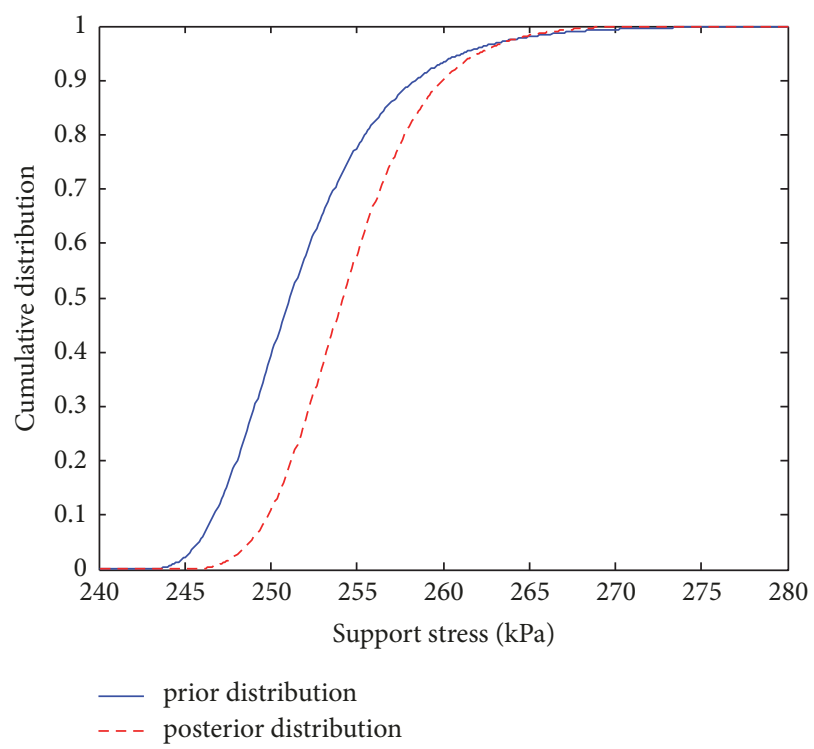

Figure 7: Cumulative distribution of the limit support stress.

\section{Conclusions}

In this paper, a Bayesian framework for updating soil strength parameters in tunnel excavation below river is presented. The method employs a MCMC simulation based approach to derive the posterior distribution of the parameters. The posterior distribution can be used for probabilistic analysis of the limit support stress on the circular tunnel face. The 3D analysis model with the limit equilibrium method is used as deterministic model. The uncertain parameters considered in the analysis are the soil strength parameters as the friction angle and cohesion. Comparing with the prior distribution, the means of prediction improve and the variation of prediction reduces by the proposed Bayesian framework. Therefore, the proposed method is effective in reducing the 
uncertainty of soil strength parameters, demonstrating its potential as a practical geotechnical engineering tool. The Bayesian framework with MCMC method might be more favorable in the uncertainty analysis and risk management.

\section{Data Availability}

The data used to support the findings of this study are available from the corresponding author upon request.

\section{Conflicts of Interest}

The authors declare that they have no conflicts of interest.

\section{Acknowledgments}

The authors sincerely acknowledge the support from the National Natural Science Foundation of China (51468041), the Specialized Research Fund for the Doctoral Program of Higher Education (20123601110001), and Jiangxi Science Foundation (20161BAB203078).

\section{References}

[1] G. Mollon, K. K. Phoon, D. Dias, and A. H. Soubra, "A new 2D failure mechanism for face stability analysis of a pressurized tunnel in spatially variable sands," in GeoFlorida 2010: Advances in Analysis, Modeling \& Design, pp. 2052-2061, 2010.

[2] A. H. Haghi, M. R. Asef, A. Taheri, and M. Mohkam, "Evaluation of the heading confinement pressure effect on ground settlement for EPBTBM Using full 3D numerical analysis," International Journal of Mining \& Geo-Engineering, vol. 47, no. 1, pp. 13-32, 2013.

[3] N. Ebadati and M. Kaboli, "Modeling stress distribution and the change of ground behavior during excavation of Tehran city underground tunnel," Journal of Geotechnical Geology, vol. 9, no. 4, pp. 293-304, 2014.

[4] G. Idinger, P. Aklik, W. Wu, and R. I. Borja, "Centrifuge model test on the face stability of shallow tunnel," Acta Geotechnica, vol. 6, no. 2, pp. 105-117, 2011.

[5] I. M. Lee, J. S. Lee, and S. W. Nam, "Effect of seepage force on tunnel face stability reinforced with multi-step pipe grouting," Tunnelling and Underground Space Technology, vol. 19, no. 6, pp. 551-565, 2004.

[6] K.-K. Phoon and F. H. Kulhawy, "Characterization of geotechnical variability," Canadian Geotechnical Journal, vol. 36, no. 4, pp. 612-624, 1999.

[7] Z. Cao and Y. Wang, "Bayesian model comparison and selection of spatial correlation functions for soil parameters," Structural Safety, vol. 49, pp. 10-17, 2014.

[8] S. E. Cho, "Effects of spatial variability of soil properties on slope stability," Engineering Geology, vol. 92, no. 3-4, pp. 97-109, 2007.

[9] C.-P. Zhang, K.-H. Han, and D.-L. Zhang, "Face stability analysis of shallow circular tunnels in cohesive-frictional soils," Tunnelling and Underground Space Technology, vol. 50, pp. 345357, 2015.

[10] G. Mollon, D. Dias, and A.-H. Soubra, "Probabilistic analysis of circular tunnels in homogeneous soil using response surface methodology," Journal of Geotechnical and Geoenvironmental Engineering, vol. 135, no. 9, pp. 1314-1325, 2009.
[11] G. Mollon, D. Dias, and A.-H. Soubra, "Probabilistic analysis of pressurized tunnels against face stability using collocationbased stochastic response surface method," Journal of Geotechnical and Geoenvironmental Engineering, vol. 137, no. 4, pp. 385397, 2011.

[12] H.-Z. Li and B. K. Low, "Reliability analysis of circular tunnel under hydrostatic stress field," Computers \& Geosciences, vol. 37, no. 1-2, pp. 50-58, 2010.

[13] P. Oreste, "A probabilistic design approach for tunnel supports," Computers \& Geosciences, vol. 32, no. 7, pp. 520-534, 2005.

[14] T. Celestino, N. Aoki, R. Silva, R. Gomes, A. Bortolucci, and D. Ferreira, "Evaluation of tunnel support structure reliability," Tunnelling and Underground Space Technology, vol. 21, no. 3-4, pp. 311-322, 2006.

[15] J. Connor Langford and M. S. Diederichs, "Reliability based approach to tunnel lining design using a modified point estimate method," International Journal of Rock Mechanics and Mining Sciences, vol. 60, pp. 263-276, 2013.

[16] Q. Lü, C. L. Chan, and B. K. Low, "System reliability assessment for a rock tunnel with multiple failure modes," Rock Mechanics and Rock Engineering, vol. 46, no. 4, pp. 821-833, 2013.

[17] A. Eshraghi and S. Zare, "Face stability evaluation of a TBMdriven tunnel in heterogeneous soil using a probabilistic approach," International Journal of Geomechanics, vol. 15, no. 6, Article ID 04014095, 2015.

[18] M. Kattwinkel and P. Reichert, "Bayesian parameter inference for individual-based models using a Particle Markov Chain Monte Carlo method," Environmental Modeling and Software, vol. 87, pp. 110-119, 2017.

[19] J. A. Vrugt, H. V. Gupta, W. Bouten, and S. Sorooshian, "A shuffled complex evolution metropolis algorithm for optimization and uncertainty assessment of hydrologic model parameters," Water Resources Research, vol. 39, no. 8, pp. 113-117, 2003.

[20] W.-H. Zhou, K.-V. Yuen, and F. Tan, "Estimation of soil-water characteristic curve and relative permeability for granular soils with different initial dry densities," Engineering Geology, vol. 179, pp. 1-9, 2014.

[21] C. Hsein Juang, Z. Luo, S. Atamturktur, and H. Huang, "Bayesian updating of soil parameters for braced excavations using field observations," Journal of Geotechnical and Geoenvironmental Engineering, vol. 139, no. 3, pp. 395-406, 2013.

[22] L. L. Zhang, Z. B. Zuo, G. L. Ye, D. S. Jeng, and J. H. Wang, "Probabilistic parameter estimation and predictive uncertainty based on field measurements for unsaturated soil slope," Computers \& Geosciences, vol. 48, pp. 72-81, 2013.

[23] H. Haario, M. Laine, A. Mira, and E. Saksman, "DRAM: efficient adaptive MCMC," Statistics and Computing, vol. 16, no. 4, pp. 339-354, 2006.

[24] G. Anagnostou and K. Kovári, "The face stability of slurryshield-driven tunnels," Tunnelling and Underground Space Technology, vol. 9, no. 2, pp. 165-174, 1994.

[25] N. Horn, "Horizontaler erddruck auf senkrechte abschlussflächen von tunnelröhren," Landeskonferenz Der Ungarischen Tiefbauindustrie, pp. 7-16, 1961.

[26] K. Terzaghi, Theoretical Soil Mechanics, John Wiley \& Sons, New York, NY, USA, 1943.

[27] J.-S. Xu, D.-C. Du, and Z.-H. Yang, "Upper bound analysis for deep tunnel face with joined failure mechanism of translation and rotation," Journal of Central South University, vol. 22, no. 11, pp. 4310-4317, 2015. 
[28] A. Gelman, J. B. Carlin, H. S. Stern, and B. R. Rubin, Bayesian Data Analysis, CRC Press, Boca Raton, Fla, USA, 2nd edition, 2004.

[29] L. L. Zhang, J. Zhang, L. Zhang, and W. H. Tang, "Back analysis of slope failure with Markov chain Monte Carlo simulation," Computers \& Geosciences, vol. 37, no. 7-8, pp. 905-912, 2010.

[30] R. Kelly and J. Huang, "Bayesian updating for one-dimensional consolidation measurements," Canadian Geotechnical Journal, vol. 52, no. 9, pp. 1318-1330, 2015.

[31] K.-K. Phoon and F. H. Kulhawy, "Evaluation of geotechnical property variability," Canadian Geotechnical Journal, vol. 36, no. 4, pp. 625-639, 1999.

[32] X. Pei, S. C. Wong, and N. N. Sze, "A joint-probability approach to crash prediction models," Accident Analysis \& Prevention, vol. 43, no. 3, pp. 1160-1166, 2011.

[33] F. Korner-Nievergelt, T. Roth, S. von Felten, J. Guélat, B. Almasi, and P. Korner-Nievergelt, Markov Chain Monte Carlo Simulation, Bayesian Data Analysis in Ecology Using Linear Models with R,BUGS, and STAN, Chapter 12, Academic Press, Boston, Mass, USA, 2015. 


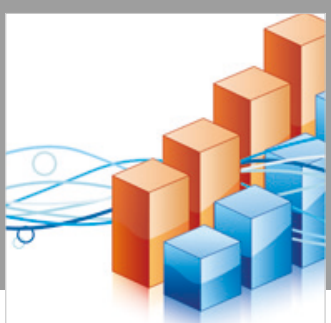

Advances in

Operations Research

\section{-n-m}
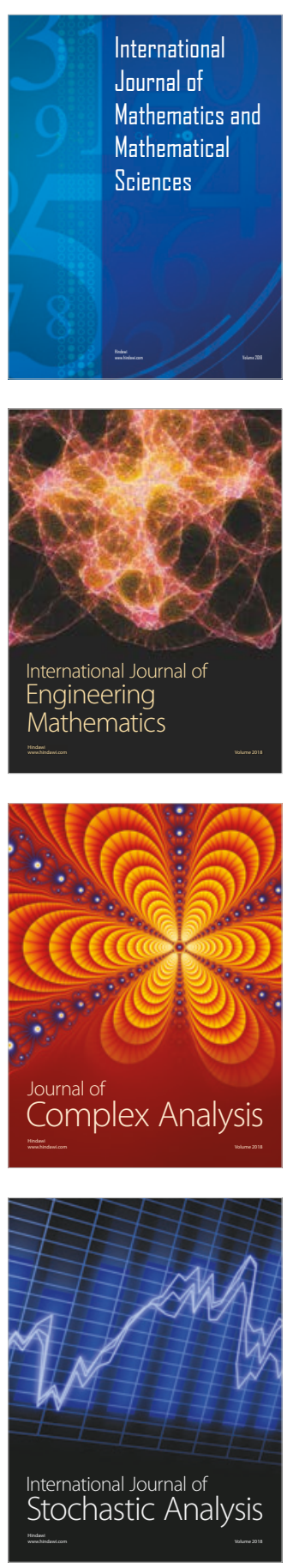
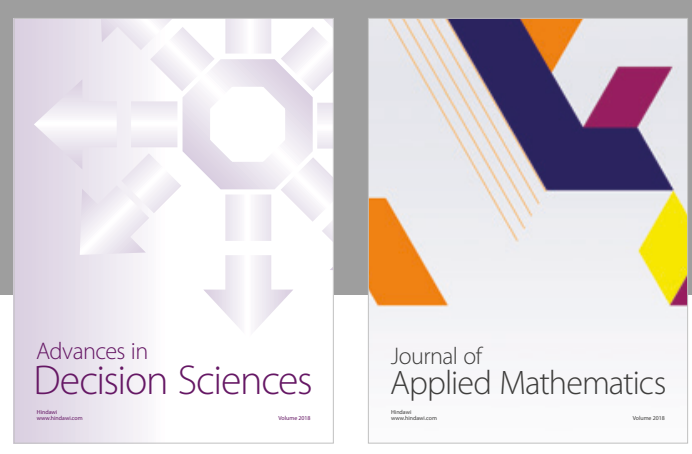

Journal of

Applied Mathematics
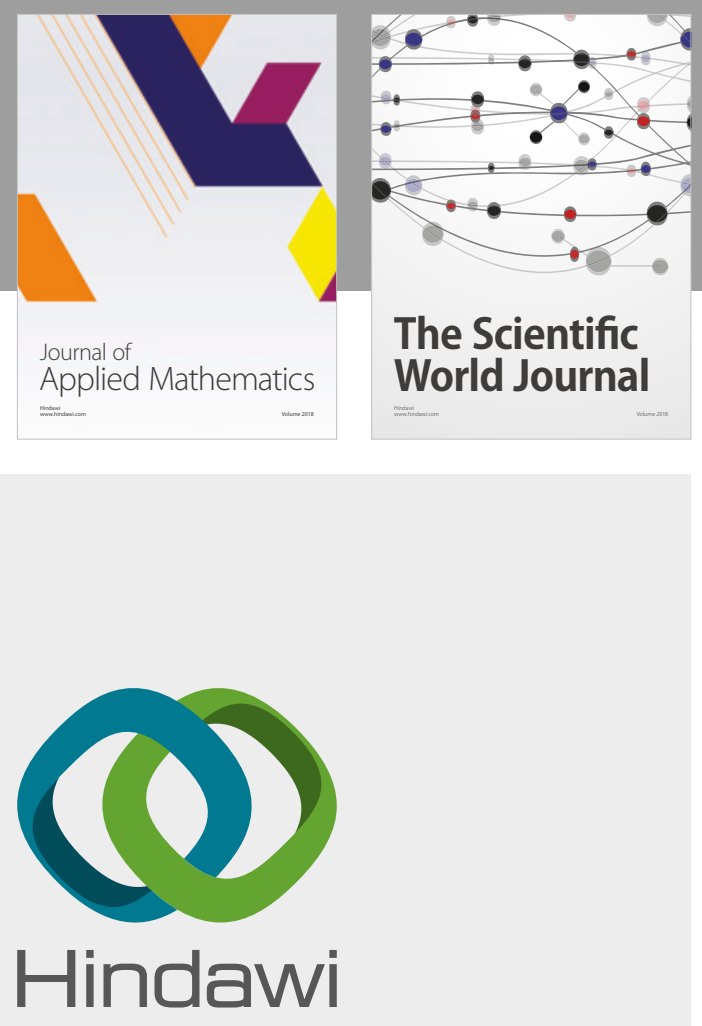

Submit your manuscripts at

www.hindawi.com

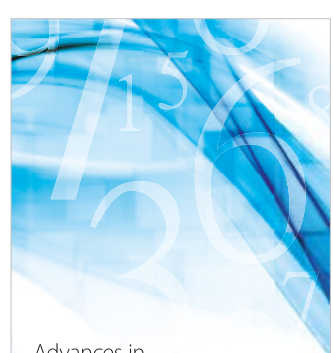

Advances in
Numerical Analysis
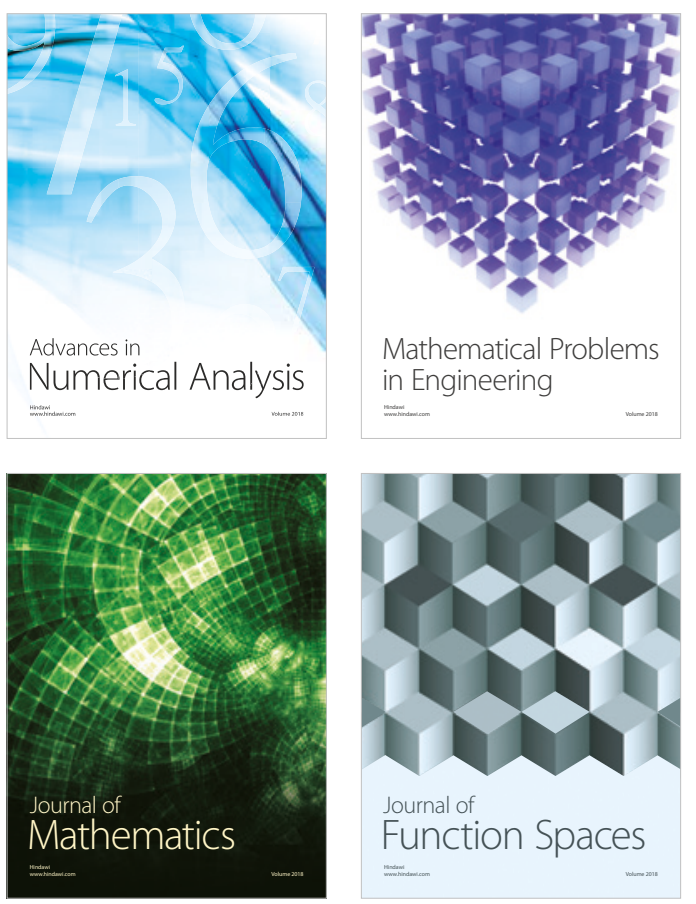

Mathematical Problems in Engineering

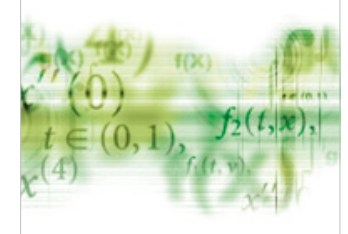

International Journal of

Differential Equations

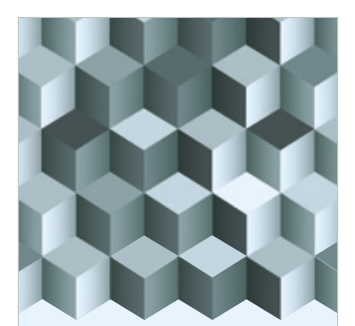

Journal of

Function Spaces

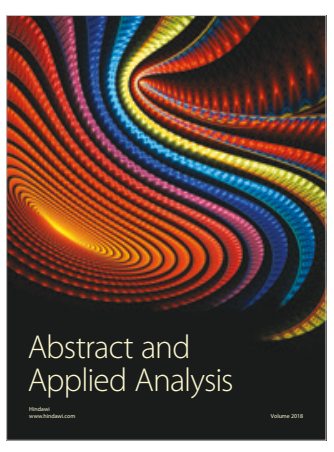

The Scientific

World Journal

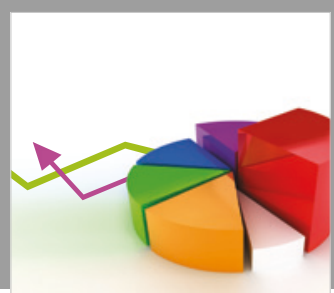

Journal of

Probability and Statistics
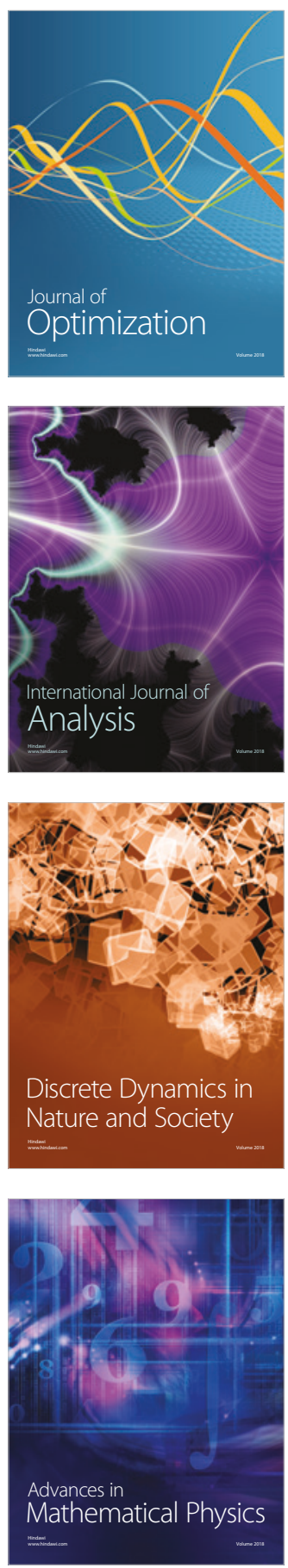